\title{
A Eficiência do Controle Social em Licitações Municipais: Um Estudo nos Observatórios Şociais
}

\author{
The Efficiency of Social Control in Municipal Bidding: A Study in Social Observatories \\ Gislaine Alves da Costa \\ Especialista em Ciências Contábeis - FURG \\ e-mail: faculdadegislaine@gmail.com \\ Daiane Pias Machado \\ Doutora em Contabilidade - UFPR \\ Universidade Federal do Rio Grande - FURG \\ Instituto de Ciências Econômicas, Administrativas e Contábeis - FURG \\ e-mail: daianepiasmachado@yahoo.com.br
}

Vanessa de Quadros Martins

Doutora em Contabilidade e Ciências Contábeis - UNISINOS

Universidade Federal do Rio Grande - FURG

e-mail: vanessa_qm@yahoo.com.br

\section{Resumo}

Este estudo aborda o controle social em sua perspectiva organizacional, avaliado a partir da atuação dos Observatórios Sociais (OBS). Os Observatórios Sociais (OBS) são entidades representativas da sociedade civil que atuam em prol da transparência e da qualidade na aplicação dos recursos públicos. Possuem a função de fomentar o controle social e o combate à corrupção. Em 2012, o trabalho desenvolvido pelos OBS impediu que o volume de 305 milhões de reais defluísse dos cofres municipais. O propósito do artigo é avaliar o nível de eficiência do controle social exercido pelos Observatórios Sociais sobre os processos licitatórios municipais. O estudo é desenvolvido sob os pressupostos da Teoria do Capital Social que assume o capital social como a capacidade de participação e associação do cidadão que estimula a cooperação gera benefícios. A amostra da pesquisa é composta por 14 Observatórios. Empregou-se a Análise Envoltória de Dados (DEA) para identificar a eficiência dos OBS do ano de 2015. Os resultados encontrados indicam que os OBS de Medianeira e Paranaguá alcançaram a máxima de eficiência na geração de economia orçamentária pelo acompanhamento das licitações e pregões. Os OBS que alcançaram média eficiência são: Porto Alegre, São José do Rio Preto e Rolim de Moura. A análise dos OBS mais eficientes permitiu observar que o alto nível de capital social empreendido pelo OBS, aliado ao nível de transparência das informações públicas e ao tamanho do município-sede, parecem estar associados aos níveis mais elevados de eficiência do controle social. Conclui-se que os OBS são importantes instrumentos de controle social e que potencializam a formação de capital social das comunidades em que estão inseridos, gerando benefícios econômicos para as administrações públicas locais e favorece a compliance e accountability na gestão de recursos públicos.

Palavras-chave: Eficiência; Controle Social; Capital Social; Observatórios Sociais.

\begin{abstract}
This study evaluates social control in its organizational perspective, assessed based on the performance of the Social Observatories (OBS). The Social Observatories (OBS) are entities representing civil society that work for transparency and quality in the application of public Submetido em 02/12/2019 e aceito em 28/06/2020 por Fernanda Sauerbronn após o processo de Double Blind Review
\end{abstract}


resources. They have the function of promoting social control and combating corruption. In 2012, the work developed by the OBS prevented the volume of 305 million reais from flowing from municipal coffers. The purpose of the article is to assess the level of efficiency of social control exercised by Social Observatories over municipal bidding processes. The study is developed under the assumptions of the Social Capital Theory that assumes social capital as the citizen's participation and association capacity that stimulates cooperation generates benefits. The research sample consists of 14 Observatories. Data Envelopment Analysis (DEA) was used to identify the efficiency of the OBS in 2015. The results found indicate that the OBS in Medianeira and Paranaguá achieved maximum efficiency in generating budget savings by monitoring bids and auctions. The OBS that achieved average efficiency are: Porto Alegre, São José do Rio Preto and Rolim de Moura. The analysis of the most efficient OBS showed that the high level of social capital undertaken by OBS, coupled with the level of transparency of public information and the size of the host city, seem to be associated with the higher levels of efficiency of social control. It is concluded that the OBS are important instruments of social control and that potentiate the formation of social capital of the communities in which they are inserted, generating economic benefits for the local public administrations and favoring compliance and accountability in the management of public resources.

key-words: Efficiency; Social control; Social Capital; Social Observatories.

\section{INTRODUÇÃO}

A administração pública brasileira tem mergulhado em uma profunda crise políticoeconômica, devido à corrupção acompanhada por estruturas institucionais ineficientes de gestão dos recursos públicos (PEREIRA, 2002). Com isso, pressões sociais têm sido imprimidas pela sociedade que clama por eficiência, eficácia e transparência na gestão dos seus recursos.

Ultimamente, a sociedade tem se apoderado daquilo que lhe foi atribuído com a institucionalização da Constituição Federal de 1988, porém poucas vezes exercido, o poder de controlar os atos praticados pela gestão pública e se manifestar contra ou a favor das ações adotadas pelo governante. O reflexo disso está nos movimentos e manifestações sociais ocorridos nos últimos anos. Assim, a sociedade brasileira demonstra estar compreendendo que o bem-estar e o desenvolvimento social é um compromisso mútuo entre os governantes - que gerenciam políticas públicas - e a sociedade - que se mobiliza para fiscalizá-las.

O controle social passa a ser percebido pela sociedade brasileira como importante aliado no alcance dos objetivos do Estado. A participação cidadã ativa na fiscalização da gestão pública e nas decisões governamentais conduz os órgãos da administração pública a uma gestão de recursos de forma responsável e contribui com a promoção de bem-estar social. De Bona e Boeira (2018) argumentam que compreender o fenômeno do controle social realizado por organizações constituídas com este propósito contribui para o avanço desse tema, com o aperfeiçoamento de iniciativas da sociedade civil e de políticas públicas de fomento à participação e accountability.

No ano de 2006 surgiram organizações sociais, conhecidas como Observatórios Sociais (OBS), com função exclusiva de fomentar o controle social sobre a administração pública municipal. A origem dessas organizações foi motivada pelos diversos casos de corrupção deflagrados envolvendo agentes públicos em diversas instituições públicas brasileiras.

Os Observatórios Sociais são organizados e conectados à Rede Observatório Social do Brasil (OSB), cujo compromisso central está no controle social, voltado à cidadania e à educação fiscal. Esses organismos têm se inserido no contexto brasileiro a partir de 2006, e suas principais iniciativas estão voltadas ao combate da corrupção, à promoção da cidadania fiscal e à avaliação da qualidade dos programas governamentais (SCHOMMER; MORAES, 
2010; DOIN; DAHMER; SCHOMMER; SPANIOL, 2012).

$\mathrm{Na}$ perspectiva do combate à corrupção, verifica-se a relevância das atividades desenvolvidas por esse tipo de organização, tendo em vista que, nos últimos anos, o Brasil tem piorado sua posição no ranking de corrupção, juntamente com os países: Austrália, Líbia, Espanha e Turquia. O ranking do nível de percepção de corrupção no setor público classifica os países em uma escala de 0 (muito corrupto) a 100 (muito limpo), no qual, em 2014 e 2015, o Brasil recebeu as pontuações de 43 e 38, respectivamente (TRANSPARENCY INTERNATIONAL, 2015).

Com o trabalho dos Observatórios Sociais no Brasil, estima-se que nos últimos quatro anos (2013-2016) a contribuição dos voluntários gerou uma economia de mais de $\mathrm{R} \$ 1,5$ bilhão aos cofres municipais (OSB, 2017). Além disso, a cada ano mais de $\mathrm{R} \$ 300$ milhões do dinheiro público deixam de serem gastos desnecessariamente. No entanto, o que se percebe como mais importante nesse contexto não são apenas os resultados financeiros, mas principalmente a nova cultura que está se formando na sociedade brasileira, que diz respeito à participação ativa do cidadão no controle da aplicação dos recursos públicos (OBSERVATÓRIO SOCIAL DO BRASIL, 2016).

Alguns estudos realizados com enfoque nos Observatórios Sociais buscaram compreender o que esses organismos de controle representam; como são instituídos; como se dá seu funcionamento e quais são as experiências voltadas à cidadania fiscal e ao controle social nos municípios.

Schommer et.al (2015) identificaram as características de coprodução de informação e controle sócio-político pelos Observatórios Sociais sobre a administração pública, considerando sua relação com órgãos de controle do governo. Concluíram que a sociedade civil que se mobiliza e se conecta ao governo local e nacional contribui para alcançar bons resultados em termos de informações públicas.

O estudo de Netto (2014) observou as estratégias utilizadas nas sociedades civis para fiscalizar o Poder Público e garantir à boa gestão pública, em especial, as redes de Amigos Associados de Ribeirão Bonito (AMARRIBO) Brasil - IFC e do Observatório Social do Brasil. Observaram a mobilização da comunidade como uma estratégia de controle visando à conscientização da importância do trabalho desenvolvido nos Observatórios Sociais. Concluíram que, em municípios de maior porte, as organizações não governamentais atuantes no controle social geralmente possuem menos conflitos com a administração pública, que tende a ser maior em municípios de menor porte.

Aguiar (2014) investigou as contribuições dos Observatórios no Brasil para a concretização da cidadania solidária. Algumas conclusões foram de que as principais ações de educação fiscal realizadas pelos Observatórios são: a promoção de palestras e eventos, concursos culturais, cursos de capacitação/assistência às empresas e servidores públicos. As principais ações voltadas à contribuição da qualidade da gestão pública são a apresentação de propostas de melhoria aos órgãos de governo; o encaminhamento de projetos de lei e a sistematização e divulgação de informações para os envolvidos com políticas públicas no município.

Este estudo aborda o controle social em sua perspectiva organizacional, avaliado a partir da atuação dos OBS. O controle social promovido pelos OBS ocorre em diversas frentes. De Bona e Boeira (2018) argumenta que alguns OS fiscalizam somente as prefeituras municipais, enquanto outros priorizam o Legislativo municipal e, alguns deles alcançam ambos os poderes, executivo e legislativo. $\mathrm{O}$ autor destaca que a maioria dos OS se limita a monitorar os editais de compras e contratações e que poucos deles conseguem acompanhar as despesas com a folha de pagamento, parcela significativa dos gastos públicos que gira em torno de $60 \%$ do orçamento municipal, entre os poderes executivo e legislativo.

O controle social no setor público tem sido abordado em diversas pesquisas (BALDISSERA, WALTER e FIIRST, 2019; DE BONA e BOEIRA, 2018; WEHN e EVERS, 
2015; SCHOMMER et al., 2015; LIU et al, 2014; SCHOMMER; MORAES, 2010), no entanto, a avaliação da eficiência desse controle, obtida pela capacidade associativa da sociedade civil e dos resultados de suas ações para a administração pública, ainda é um ponto a ser explorado pela comunidade científica e se constitui na lacuna dessa pesquisa. Silva Filho (2017) argumenta que mensurar o grau de eficiência dos meios de controle social das licitações como boa prática da administração pública é um desafio a ser perseguido.

Para preencher essa lacuna de pesquisa, esse estudo se destina a responder ao seguinte questionamento: em que medida o controle social exercido pelos Observatórios Sociais sobre os processos licitatórios dos municípios brasileiros é eficiente? Portanto, o objetivo principal dessa pesquisa é avaliar o nível de eficiência do controle social exercido pelos Observatórios Sociais sobre os processos licitatórios municipais. Em adição, dados demográficos municipais foram analisados a fim de verificar uma possível relação entre as características demográficas das cidades e a eficiência do Observatório Social no controle dos processos licitatórios, dado que o porte do município pode estar associado ao maior ou menor grau de conflitos gerados entre a administração pública municipal e o OS (Netto, 2014) e isso pode influenciar na eficiência do controle social.

O controle social é efetivo quando seus atos conduzem a Administração Pública à observação dos princípios constitucionais da legalidade, moralidade, publicidade e eficiência. A eficiência na administração pública é obtida pela maximização da produção de bens e serviços acompanhada da minimização dos custos (SILVA FILHO, 2017). As licitações públicas são os instrumentos pelos quais a administração pública procura obter o maior volume de bens e serviços pelo menor custo de aquisição ou construção. Avaliar a economia gerada nas licitações acompanhadas pelos observatórios sociais pode auxiliar na compreensão e mensuração do grau de eficiência do controle social das licitações públicas e os benefícios gerados para a administração pública.

A principal contribuição desse estudo está em avaliar e disseminar à comunidade científica, bem como à sociedade em geral constatações empíricas sobre o nível de eficiência do controle dos observatórios sociais sobre os processos licitatórios municipais promovendo uma discussão oportuna sobre o potencial dessas instituições de gerar ganhos para a sociedade ao promover, entre outros aspectos, o exercício da cidadania fiscal brasileira.

Nessa pesquisa, os Observatórios Sociais são vistos como agentes de fomento à formação de redes colaborativas na sociedade civil. Putnam (2000) argumenta que essa capacidade de associação entre a comunidade é percebida como seu capital social. O capital social é definido por Putnam (2000) como um sistema de participação e associação que estimula a cooperação. Quanto maior e mais rico for o número de possibilidades associativas em uma sociedade, maior será o seu volume de capital social. Nesse contexto, os Observatórios Sociais podem ser vistos como a materialização do capital e do controle social, na medida em que os cidadãos se unem, formando rede de cooperação social em prol de um benefício coletivo.

\section{TEORIA DO CAPITAL SOCIAL}

Capital social pode ser entendido como relações mútuas que contribuem para a conservação de normas sociais (reciprocidade), informação e confiança presentes nas redes informais desenvolvidas pelos indivíduos (BOURDIEU, 1980).

Pierre Bourdieu (1980) foi o precursor na análise contemporânea do capital social, definindo-o como um conjunto de recursos efetivos ou potenciais ligados a uma rede de relações de conhecimento ou reconhecimento mútuo. Para o autor, o Capital Social está centrado nos benefícios obtidos pelos indivíduos em virtude da participação em grupos e, da construção de sociabilidades tendo em vista a criação de capital social. 
O termo capital social foi desenvolvido em diversas análises sociológicas ao longo dos anos. Coleman (1988) definiu capital social como um conjunto de entidades com elementos em comum que facilitam determinadas ações dos atores no interior da estrutura social. Baker (1990) definiu capital social como recursos criados por alterações nas relações entre atores, derivados de estruturas sociais específicas, que são usados para a realização dos seus interesses.

Schiff (1992), por sua vez, descreve o capital social como um conjunto de elementos da estrutura social que afetam as relações entre pessoas e que são oriundos da função de utilidade. Apesar das diversas abordagens do termo Capital Social, parece haver um consenso no entendimento de que consiste na capacidade de os atores garantirem benefícios em virtude da sua inserção em redes ou estruturas sociais. É neste sentido que o conceito tem sido frequentemente usado em investigações desse tema (Portes, 2000).

A abordagem do Capital Social na ciência política deu-se por sua interligação ao nível de "civismo" em comunidades como vilas, cidades, ou mesmo países inteiros. Robert Putnam foi o defensor desta abordagem. Para este autor, o capital social consiste em características de organizações sociais, como redes, normas e confiança, que facilitam a ação e a cooperação com vista a um benefício mútuo (Putnam, 2000).

Portes (2000) argumenta que o volume de capital social de uma comunidade pode ser identificado com o nível de envolvimento associativo e de comportamento participativo de uma comunidade. Como indicadores destaca-se: a participação em associações voluntárias e a expressão de confiança nas autoridades políticas.

A tese central de Putnam repousa na circularidade entre a formação de capital social e o desenvolvimento econômico local. Para o autor, o capital social é simultaneamente uma causa e um efeito. Ao mesmo tempo em que conduz a resultados positivos, como o desenvolvimento econômico, tem a sua existência auferida desses mesmos resultados. O autor fundamenta sua tese a partir da observação da força/fraqueza das comunidades cívicas de algumas regiões da Itália. O autor observa que cidades com um elevado capital social são bem governadas e apresentam um elevado progresso econômico, em contraste com cidades mais pobres que não possuem esta virtude cívica bem desenvolvida (Putnam, 2000).

Santos e Nunes (2013) consideram que o capital social é próprio da cultura política local (região e cidade) e constitui- se em um aliado às instituições políticas, pois está associado à avaliação positiva das políticas públicas municipais, que em uma de suas formas de capital social - normas e sanções - encorajam os indivíduos a trabalharem pelo bem comum.

Fernández e Estrada (2018) operacionalizaram o conceito de Capital Social a partir da avaliação da capacidade cooperativa dos indivíduos em busca de projetos coletivos em benefício de sua comunidade. Para isso, os autores realizaram entrevistas com 356 pessoas de 49 municípios espanhóis e desenvolveram vários indicadores para medir o nível de capital social destas comunidades. Os autores constataram que as comunidades avaliadas apresentaram um nível médio-baixo de capital social em relação ao grau de confiança entre os moradores, ao grau de participação em atividades coletivas, ao grau de identidade regional, ao grau de confiança em instituições e à percepção de eficiência das instituições. Quanto ao grau de cooperação entre instituições no âmbito associativo e entre municípios os autores constataram um nível baixo de capital social.

Xeres e Fonseca (2019) analisaram a importância do capital social e das redes de vizinhança no bairro de Alvalade, em Lisboa. Os resultados encontrados revelam que a dinâmica do capital social e das redes de vizinhança está ligada a diferenças na estrutura, confiança e reciprocidade, assim como nos recursos e envolvimento dos residentes do bairro analisado.

O avanço democrático das últimas décadas tem criado demanda crescente da sociedade sobre o Estado e suas instituições políticas, do qual têm exigido da administração pública políticas mais eficientes e eficazes, em que uma parcela cada vez maior da população brasileira 
vem sendo incorporada pelo Estado por meio de suas políticas públicas (SANTOS; NUNES, 2013).

Alguns benefícios econômicos relacionados ao capital social são a melhor coordenação e coerência das ações públicas, processos de tomada de decisão coletivos e maior conhecimento mútuo, que aumenta previsibilidade e diminuem comportamentos oportunistas (ALBAGLI; MACIEL, 2003), com isso, o desempenho do governo pode estar associado ao capital social empregado em Observatórios Sociais.

O capital social como temática de pesquisas vem recebendo atenção em várias áreas do conhecimento, além de organizações públicas e privadas. Dentre algumas razões para a difusão do conceito de capital social destaca-se o crescente ambiente político-econômico que tem levado a um reposicionamento do papel do Estado e da sociedade, bem como das relações entre o público e o privado e o potencial político (ALBAGLI; MACIEL, 2001).

Monastério (2002) indicou a hipótese de que a falta de capital social do tipo bridging e linking é a razão da decadência relativa na região Sul do Rio Grande do Sul, conhecida como Campanha. Baquero (2003) indagou a relação entre democracia, cultura política e capital social no Brasil. Os resultados do estudo sugeriram a existência de cultura política pouco participativa ao mesmo tempo em que indicou a necessidade da organização de grupos sociais já existentes, promover a formação de associações para alcançar metas instrumentais e criar condições para uma cooperação mais ampla ou o capital social público. Concluiu também que o capital social como instrumento de empowerment das pessoas que agem coletivamente pode ser o mecanismo que faltava para gerar uma democracia mais eficiente e com qualidade, a ponto de que as experiências da sociedade na participação social fortaleçam o conceito de cidadania.

Para Motta (2007) o capital social, no geral, sugere que aumentando a capacidade associativa de um grupo, comunidade ou rede de participantes reduzem as desigualdades de acesso aos benefícios sociais, que permite maior igualdade de oportunidades aos membros. Ampliando estas possibilidades através do acesso aos ativos sociais, a pobreza é reduzida.

Quando Putnam (2000) considera o capital social como um sistema de participação e associação que estimula a cooperação, depreende-se que quanto maior e mais rico for o número de possibilidades associativas em uma sociedade, maior será o seu volume de capital social. Nesse contexto, os Observatórios Sociais podem ser vistos como a materialização do capital e do controle social, na medida em que os cidadãos se unem, formando uma rede de cooperação social em prol de um benefício coletivo.

\subsection{Controle Social}

Controle social é ato realizado individual ou coletivamente pelos membros da sociedade através dos diversos instrumentos jurídicos colocados ao cidadão para fiscalizar, vigiar, velar, examinar, inquirir e colher informações a respeito do exercício da função administrativa do Estado (SIRAQUE, 2005).

A concepção de controle social está relacionada à participação dos cidadãos na administração pública, intervindo na tomada de decisão e direcionando os gestores em medidas que garantam o alcance do bem comum e ao interesse público. Envolve a físcalização dos recursos públicos, sob a perspectiva da legalidade, legitimidade, economicidade e oportunidade (ALVES, 2015).

Nesse sentido, o controle social contribui com a qualidade na aplicação de recursos públicos, promovendo o desenvolvimento da cidadania consciente (ALVES, 2015). A participação social na gestão pública constitui um mecanismo de controle social que exige maior eficiência dos agentes envolvidos na administração (ALVES, 2015).

A eficiência na gestão dos recursos públicos é alcançada quando o administrador público considera os critérios de razoabilidade e de proporcionalidade na prática dos atos de gestão pública, com vistas a atender ao interesse público em sua plenitude. Nesse sentido, o 
aumento da eficiência do Estado se relaciona diretamente com a essencialidade do próprio controle social ao buscar a manutenção da coerência do ato administrativo, satisfazendo o interesse público (SILVA FILHO, 2017).

A efetividade do controle social requer a otimização de seu exercício, para que o controle jurisdicional seja provocado a se opor aos atos de desvio de poder ou finalidade. Com isso, torna-se imprescindível a ampliação e disponibilização dos meios de comunicação entre o Estado e a sociedade civil e dos demais órgãos de controle da Administração Pública, para que atuem como parceiros na tarefa de fiscalização da gestão pública (SILVA FILHO, 2017). Nesse aspecto, a transparência funciona como mecanismo operacional para o controle social, pois possibilita ao cidadão o acompanhamento e análise da gestão pública e suas operações (ZANETTI; BONZANINI; FERREIRA, 2020).

Em contrapartida, a falta de mecanismos que favoreçam o controle social, assim como a ineficácia dos mecanismos existentes e disponíveis, provocam o desestímulo e a conformação do cidadão frente aos atos de improbidade praticados no âmbito da Administração Pública. Assim, o Estado deve criar mecanismos facilitadores da comunicação com a sociedade, ampliando as opções de participação social, capazes de gerar resultados com accountability, disclosure, compliance. (SILVA FILHO, 2017). Baldissera, Walter e First (2019) analisaram a percepção dos Observatórios Sociais brasileiros sobre a qualidade, utilidade e suficiência das informações divulgadas pelos municípios. Os autores concluíram que na percepção dos Observatórios sociais, a qualidade das informações divulgadas pelas administrações públicas não atende aos objetivos da Lei de Acesso à Informação e que as informações divulgadas pelos canais de transparência pública são insuficientes para promover o controle social.

Para fortalecer os mecanismos de controle social, Mamedova et al. (2017) propõem o uso de serviços de automação para apoiar o monitoramento dos contratos de compras. Os autores destacam que as áreas que devem implementar medidas de controle social incluem: planejamento, compras e realização de contratos. (MAMEDOVA et al, 2017).

Nessa linha, com o objetivo de aprimorar os mecanismos de monitoramento e combate à corrupção e estender a transparência do Estado aos funcionários da administração pública e da sociedade em geral, em 2008, a Controladoria Geral da União (CGU) estabeleceu o Observatório da Despesa Pública (ODP). Descrito pela CGU como um projeto com potencial para usar a tecnologia da informação para monitorar e analisar os gastos do governo. O ODP é projetado para identificar situações que podem constituir impropriedades ou irregularidades. Em geral, o ODP permite a identificação de inconsistências que podem abrir caminho para o mau uso de fundos públicos (De BARROS; CAMARGO, 2012).

Schommer et.al (2015) identificaram as características de coprodução de informação e controle sócio-político exercido pelos Observatórios Sociais sobre a administração pública. Concluíram que a sociedade civil que se mobiliza e se conecta ao governo local e nacional contribui para alcançar bons resultados em termos de informações públicas.

O controle social dos gastos públicos submete os agentes públicos ao crivo social e ocorre em três momentos distintos: prévio, concomitante ou subsequente. O controle prévio ocorre anterior à liquidação da despesa, em que eventuais irregularidades são apuradas pregressas da sua execução, pode-se citar a análise de contratos administrativos. O controle é concomitante quando existe o acompanhamento, fiscalização e denúncia durante a execução dos e gastos governamentais, neste caso há um importante papel de transparência pública. Considera-se subsequente o controle da avaliação de resultados, desempenhos e eficiência da gestão pública, que se realiza após da efetivação da despesa (QUINTANA; MACHADO; QUARESMA; MENDES, 2015).

O controle social é efetivo quando seus atos conduzem a Administração Pública à observação dos princípios constitucionais da legalidade, moralidade, publicidade e eficiência. 
A máxima eficiência obtida pela administração pública persegue a maximização da produção de bens e serviços acompanhada da minimização dos desperdícios. A eficiência é concretizada no incremento da relação custo-benefício nos atos administrativos. As licitações públicas são os instrumentos pelos quais a administração pública persegue a economia na realização de gastos públicos. Portanto, a sustentabilidade das licitações públicas é um dos elementos conduzem à eficiência no setor público (SILVA FILHO, 2017).

A eficiência das licitações se traduz pela excelência na consecução de seus objetivos, ao ser capaz de selecionar a proposta mais vantajosa para a Administração Pública, conforme critérios de máxima objetividade e relevantes custos-benefícios sociais, ambiental e econômicos. Silva Filho (2017) argumenta que mensurar o grau de eficiência dos meios de controle social das licitações como boa prática da administração pública é um desafio a ser perseguido. Assim, avaliar a economia gerada nas licitações acompanhadas pelos observatórios sociais pode auxiliar na compreensão da eficiência do controle social em licitações e indicar seus benefícios para a administração pública.

O trabalho desenvolvido pelos Observatórios Sociais, em geral, ocorre nos três momentos descritos, no entanto, é no controle concomitante que esses organismos conseguem alcançar resultados mais favoráveis em termos de economia orçamentária, pois inibem o desperdício de dinheiro público ao denunciar equívocos licitatórios ou atos ilícitos praticados.

A pesquisa de Zanetti, Bonzanini e Ferreira (2020) teve por objetivo identificar as contribuições dos Observatórios Sociais do Brasil para o exercício da transparência e do controle social na gestão pública. Os autores concluíram que as contribuições dos Observatórios Sociais para a gestão pública consistem na redução de custos, prevenção de irregularidades, promoção da cidadania e foco na transparência dos processos públicos.

\subsection{Observatórios Sociais}

O Observatório Social (OS) é um espaço democrático e apartidário, que reúne um número significativo de entidades representativas da sociedade civil. Atua em favor da transparência e da qualidade na aplicação dos recursos públicos, utilizando metodologias eficientes no monitoramento das compras e dos contratos celebrados pelo município. Há um esforço na participação ativa de fiscalização e orientação da cidadania e controle social nas condutas públicas. Além disso, contribui para a educação da população local revelando a importância de cada cidadão em fiscalizar, monitorar a produção legislativa municipal e controlar as atividades e investimentos públicos (OBSERVATÓRIO SOCIAL DO BRASIL, 2015).

Embora os Observatórios não possam exercer sanção direta sobre os gestores da administração pública, suas ações podem mobilizar e influenciar outros instrumentos de accountability - como o controle institucional - além de influenciar as eleições e as regras estatais intertemporais, gerando efeitos mais amplos sobre a cidadania e a democracia de uma cidade ou de um país (ABRUCIO; LOUREIRO, 2005; SCHOMMER; MORAES, 2010).

Aguiar (2014) considera que a principal motivação para a implantação do OS é o incentivo de cidadãos ligados a instituições semelhantes em município vizinho ou do Observatório Social do Brasil, confirmando a importância da rede e da colaboração entre as organizações. Além disso, demonstra que as entidades mais atuantes na implantação dos OS são associações, cooperativas, federações e sindicatos de trabalhadores ou profissionais liberais, que de forma geral, se relacionam com conhecimentos necessários para o desempenho das atividades nos Observatórios. Perante isso, membros das equipes desta rede são predominantemente formados em Direito, Contabilidade, Economia e Administração. 
A implantação de um Observatório Social envolve alguns passos de conhecimentos de educação fiscal e do controle social. Para a efetivação é necessária a dedicação da comunidade que sediará o Observatório, em especial de lideranças da sociedade civil organizada. Os passos podem ser sintetizados com o envolvimento de assessoria de instituições que desenvolvem trabalho semelhante (FERREIRA; TRECCO; CARNEVALE; OTERO, 2012).

Para o Observatório Social do Brasil (2015), os municípios brasileiros que possuem OS têm benefícios não só para os cidadãos, mas também as empresas na região. Segundo os dados apresentados em outros Observatórios, cidades sem OS, possuem uma média de três empresas em processos licitatórios e cidades que têm em média sete empresas concorrem a cada licitação. Com um Observatório presente no município, há aumento na concorrência nas licitações, beneficiando mais empresas. Os Observatórios também contam com diversos programas para capacitar as empresas e melhorar os processos licitatórios. Havendo maior transparência e informação aos cidadãos através da capacitação e a publicação dos indicadores sociais do município.

Através de uma metodologia padronizada, os Observatórios Sociais monitoram as contas públicas do município, desde a transparência na publicação do edital de licitação até a entrega do produto ou a total prestação de serviço contratados, acompanham todos os procedimentos para verificar se não houve irregularidades até a entrega final do produto ou da prestação de serviço. De acordo com reportagem da Revista Veja, o Observatório Social do Brasil, conseguiu em 2012 impedir que o volume de 305 milhões de reais defluísse dos cofres municipais.

Boas práticas já podem ser observadas como resultados alcançados pela rede de OS. O Observatório de Londrina conseguiu impugnar vários processos licitatórios com irregularidades, em Campo Largo e Marechal Rondon realizou-se um projeto de conscientização da educação para a cidadania fiscal cujos principais objetivos foram de esclarecer a arrecadação de impostos e o papel do cidadão na sociedade, através de um teatro de fantoches.

No município de Castro foi firmado o Termo de Ajustamento de Conduta com a Prefeitura, aos moldes do realizado pelo Ministério Público, com o objetivo de ajustar alguns prazos para adaptação de entrega dos ofícios por parte do Poder Público e o não cumprimento parcial ou integral das obrigações assumidas no termo implicaria em uma multa diária de $\mathrm{R} \$ 500,00$ (quinhentos reais) por dia. Em Campo Mourão conseguiu-se aumentar a concorrência e fazer com o que a prefeitura economizasse recursos públicos ao questionar vários processos licitatórios (CARNEIRO, 2015).

\section{PROCEDIMENTOS METODOLÓGICOS}

Esta seção apresenta os procedimentos utilizados na pesquisa a fim de cumprir o objetivo de avaliar o nível de eficiência do controle social exercido pelos observatórios sociais sobre os processos licitatórios municipais, para tanto, a técnica utilizada foi a Análise Envoltória de Dados (DEA), por meio da qual se realizou uma observação cross section do ano de 2015 das variáveis selecionadas para o estudo. A pesquisa é de natureza exploratória, quantitativa e com delineamento documental.

Como fonte de dados foram utilizados os relatórios quadrimestrais dos OS, coletados no site do Observatório Social do Brasil, dos quais foram extraídas informações sobre a economia em relação às licitações e aos pregões acompanhados dos poderes executivo e legislativo, bem como a economia nas irregularidades encontradas na entrega de bens e prestações de serviços. 
A amostra está composta somente pelos Observatórios Sociais cujos relatórios apontam o acompanhamento e obtenção de economia nas licitações e pregões no ano de 2015 . O levantamento dos relatórios quadrimestrais dos OS de 2015 indicou um total de 17 Observatórios, dentre os quais alguns prestaram contas em todos os quadrimestres do ano e outros somente em um ou dois quadrimestres, dessa forma, identificaram-se 35 relatórios, dos 17 Observatórios, que indicaram o valor da economia das licitações e pregões acompanhados.

Entretanto, para a consecução da amostra, foram excluídos três Observatórios Sociais, o Observatório de Indaial em Santa Catarina, pela ausência da informação sobre o número da equipe de trabalho e os Observatórios de Foz do Iguaçu e Guarapuava do Estado do Paraná pela ausência do valor da economia monetária das licitações e pregões no período de 2015, desta forma o número de Observatórios passou de 17 para 14. Na Figura 1 apresentam-se os Observatórios Sociais que integraram a amostra da pesquisa.

\begin{tabular}{|ll|}
\hline Estados & Observatórios Sociais (município) \\
\hline & Arapongas \\
& Palmeira \\
& Ponta Grossa \\
Paraná & Irati \\
& Mandaguari \\
& Marechal Cândido Rondon \\
& Medianeira \\
& Paranaguá \\
\hline Santa Catarina & Imbituba \\
\hline Rio Grande do Sul & Porto Alegre \\
\hline Rio de Janeiro & Erechim \\
\hline Rondônia & Teresópolis \\
\hline São Paulo & Rolim de Moura \\
\hline
\end{tabular}

Figura 1 - Amostra da pesquisa

Fonte: Elaborado pelas autoras.

Para complementar a discussão em torno da eficiência do controle social sobre os processos licitatórios, foram analisadas variáveis do perfil demográfico dos municípios que integraram a amostra da pesquisa. Para isso, foram coletados os dados relativos: ao último PIB dos Estados e Municípios, sendo esse referente ao ano de 2013; a estimativa da população municipal no ano de 2015; ambos coletados no site do Instituto Brasileiro de Geografia e Estatística (IBGE). Também foi analisado o índice de transparência municipal, fornecido no site do Ministério Público Federal.

A Análise Envoltória de Dados (DEA - sigla em inglês, Data Envelopment Analysis) constitui-se em uma técnica matemática, não-paramétrica utilizada para medir a eficiência relativa de várias unidades mediante a consideração explícita do uso de múltiplas entradas (inputs) para a produção de múltiplas saídas (outputs) (CHARNES; COOPER; RHODES, 1978). Nela, o conceito de Eficiência compara o que foi produzido, dados os recursos disponíveis, com o que poderia ter sido produzido com os mesmos recursos.

Existem dois modelos de base do DEA: CCR/CRS (Constant Returns to Scale) e BCC/VRS (Variable Returns to Scale), o primeiro é utilizado para reduzir os inputs, mantendo o nível de produção e segundo aumenta a produção e níveis de insumos (CHARNES; COOPER; RHODES, 1978). O modelo empregado foi o CCR/CRS, utilizado para indicar uma medida de produtividade global. Essa técnica estatística requer a definição da orientação da medida de eficiência, se para o input ou output.

De acordo com Almeida, Mariano e Rebelatto (2006), essa orientação é definida na configuração do problema da pesquisa, neste caso, o modelo escolhido para a orientação da 
fronteira de eficiência neste estudo foi para output, aplicado quando se busca maximizar o resultado, sem modificar os recursos empregados, ou seja, maximizando a economia orçamentária (output), sem necessariamente modificar o volume de licitações e de pessoas que trabalha do OS (input).

O processamento dos dados foi realizado com a utilização do software Frontier Analyst@. As Unidades Tomadoras de Decisão (Decision Making Units - DMUs) correspondem os Observatórios Sociais que executaram e relataram a economia nas licitações e pregões acompanhados.

A Teoria do Capital Social constitui o delineamento teórico que subsidiou a escolha dos inputs e outputs utilizados para o cálculo da eficiência dos OBS. Na perspectiva de Bourdieu (1980) e Putnam (2000), o capital social pode ser definido como um sistema de participação e associação que estimula a cooperação dos indivíduos de uma sociedade e que gera benefícios coletivos em virtude do envolvimento em grupos constituídos para propósitos sociais. Portes (2000) complementa que o Capital Social consiste na capacidade de os atores garantirem benefícios em virtude da sua inserção em redes ou estruturas sociais.

Neste sentido, a eficiência do controle social no acompanhamento das licitações públicas realizado nos OBS foi avaliada a partir do potencial de capital social empreendido por este organismo social (inputs) e o resultado por eles gerados (output). O potencial de capital social dos OBS (inputs) foi estimado pelo número de pessoas que compõe a equipe de trabalho do OBS e pelo número de licitações acompanhadas por elas. Os resultados (output) foram avaliados a partir da economia orçamentária gerada aos cofres públicos nas licitações acompanhadas.

A seleção das variáveis para o processamento do cálculo da eficiência levou em consideração, também, o propósito dessas instituições de atuar em favor da qualidade na aplicação dos recursos públicos mediante o monitoramento das compras e dos contratos celebrados, que constituem o programa número 1 dos Observatórios Sociais. Dessa forma, as variáveis utilizadas para o cálculo da eficiência foram selecionadas desse programa 1 dos Observatórios Sociais "Qualidade na aplicação dos recursos públicos - monitoramento das licitações.

De acordo com a prestação de contas do Observatório Social do Brasil de 2015, a economia gerada pelo trabalho dos OS nas licitações acompanhadas foi de 10 a $15 \%$ e o orçamento anual de compra nas 105 cidades onde possuem OS, que corresponde a cerca de 34 bilhões de reais. Devido à sua importância monetária, a economia obtida no acompanhamento dos processos licitatórios representa uma variável observada nesse estudo para avaliar a eficiência desta instituição no controle social. Tal economia é gerada a partir do controle social realizado pelo trabalho de voluntários em Observatórios Sociais que fiscalizam editais e pregões com o intuito de detectar possíveis irregularidades e solicitar ao poder público que realize os ajustes necessários.

Essa variável de economia orçamentária refere-se ao valor economizado pela administração pública, a partir da irregularidade encontrada pelo OS, referente as licitações e pregões que seguiram até a fase de adjudicação cujo valor final foi inferior ao valor inicial, ou seja, representa a diferença entre valor máximo estimado e licitado. Esta definição encontra-se na orientação normativa $\mathrm{n}^{\circ} 03$ do Observatório Social do Brasil (OSB), com a finalidade de garantir o alinhamento da rede relativo ao programa 1 dos OS. O conceito de economia do OSB foi utilizado na coleta e tratamento dos dados, que levou também em consideração licitações com irregularidades que obtiveram devolução monetária foi instrumentalizado mediante a seguinte fórmula:

$$
\text { ETO = VTE - VTL - DI (1) }
$$


Em que:

ETO: Economia total obtida;

VTE: Valor total estimado;

VTL: Valor total licitado e;

DI: Devolução por irregularidade.

Na Figura 2 apresentam-se as variáveis utilizadas para o cálculo da eficiência dos OS, que se justificam por refletir o escopo do seu programa 1.

\begin{tabular}{|c|c|c|}
\hline Empregabilidade no modelo & Inputs & Outputs \\
\hline Variáveis & $\begin{array}{ll}\checkmark \quad \mathrm{N}^{\circ} \text { de pessoas que integram o } \\
\quad \text { Observatório (Inputl) } \\
\checkmark \quad \mathrm{N}^{\circ} \text { de licitações e pregões } \\
\text { acompanhados (Input2) }\end{array}$ & $\begin{array}{ll}\checkmark & \text { Valor da economia obtida das } \\
& \text { licitações (Outputl) }\end{array}$ \\
\hline
\end{tabular}

Figura 2 - Variáveis utilizadas para avaliação da eficiência

Considerando o propósito dos OS ensejar a qualidade na aplicação dos recursos públicos mediante o monitoramento das compras e dos contratos celebrados, assume-se nessa pesquisa que o número de pessoas que integra o OS para monitorar as compras e contratos públicos, bem como o número de licitações e pregões acompanhados, correspondem aos recursos necessários para alcançar economia orçamentária, contribuindo com o alcance dos resultados esperados pelos OS. Portanto, a equipe de trabalho dos OS e o número de licitações e pregões acompanhados constituem os inputs no modelo de eficiência do controle social a partir do trabalho desenvolvido nos OS. Já o valor da economia orçamentária é o output para a análise da eficiência, tendo em vista que a redução de custos, implica na economia orçamentária, é uma das principais contribuições dos observatórios sociais indicadas por Zanetti, Bonzanini e Ferreira (2020).

\section{ANÁLISE DOS RESULTADOS}

A análise dos dados está segregada em três momentos. No primeiro deles se apresenta o perfil demográfico dos municípios que possuem Observatórios Sociais sob análise; em seguida, se discutem as informações relativas as variáveis utilizadas na pesquisa. Por fim, apresentam-se os escores de eficiência dos OS analisados.

\subsection{Perfil Demográfico Dos Municípios}

As variáveis escolhidas para compor o perfil demográfico dos municípios que será explorado na pesquisa estão apresentadas na Tabela 1.

Tabela 1 - Perfil demográfico dos municípios com Observatórios Sociais

\begin{tabular}{l|l|r|r|r|r}
\hline Estados & \multicolumn{1}{|c|}{ Municípios } & $\begin{array}{c}\text { População } \\
\text { municipal }\end{array}$ & $\begin{array}{c}\text { PIB } \\
\text { Municipal per } \\
\text { capita } \\
\text { (R\$ 1,00) }\end{array}$ & $\begin{array}{c}\text { Participação } \\
\text { do PIB do } \\
\text { Estado (\%) }\end{array}$ & $\begin{array}{c}\text { Índice de } \\
\text { Transparência } \\
\text { Municipal }\end{array}$ \\
\hline \multirow{2}{*}{ Paraná } & Arapongas & 115.412 & 33.690 & 1,03 & 7,20 \\
& Irati & 59.708 & 24.840 & 0,39 & 7,00 \\
& Mandaguari & 34.289 & 34.015 & 0,31 & 6,90 \\
& Marechal Cândido & 50.808 & 36.054 & 0,49 & 8,90 \\
Rondon & 44.885 & 33.024 & 0,40 & 6,90
\end{tabular}




\begin{tabular}{|c|c|c|c|c|c|}
\hline Estados & Municípios & $\begin{array}{l}\text { População } \\
\text { municipal }\end{array}$ & $\begin{array}{c}\text { PIB } \\
\text { Municipal per } \\
\text { capita } \\
(\mathbf{R} \$ 1,00) \\
\end{array}$ & $\begin{array}{c}\text { Participação } \\
\text { do PIB do } \\
\text { Estado }(\%)\end{array}$ & $\begin{array}{c}\text { Índice de } \\
\text { Transparência } \\
\text { Municipal }\end{array}$ \\
\hline & Palmeira & 33.753 & 30.476 & 0,27 & 6,70 \\
\hline & Paranaguá & 150.660 & 46.973 & 1,88 & 4,80 \\
\hline & Ponta Grossa & 337.865 & 34.941 & 3,13 & 4,10 \\
\hline Santa Catarina & Imbituba & 43.168 & 26.048 & 0,45 & 6,40 \\
\hline \multirow{2}{*}{ Rio Grande do Sul } & Erechim & 102.345 & 41.645 & 1,12 & 4,90 \\
\hline & Porto Alegre & 1.476 .867 & 46.122 & 17,83 & 10,00 \\
\hline Rio de Janeiro & Teresópolis & 173.060 & 29.008 & 0,76 & 5,20 \\
\hline Rondônia & Rolim de Moura & 56.242 & 19.714 & 3,03 & 0,80 \\
\hline São Paulo & S. José do Rio Preto & 442.548 & 33.784 & 0,77 & 9,00 \\
\hline
\end{tabular}

Fonte: Dados da pesquisa.

Os maiores municípios em termos populacionais da amostra são: Porto Alegre, São José do Rio Preto e Ponta Grossa. Os menores municípios analisados foram: Palmeira, Mandaguari e Imbituba. Os municípios com maior PIB municipal per capita são: Paranaguá, Porto Alegre e Erechim. Os municípios que apresentam menor PIB municipal per capita são: Rolim de Moura, Irati e Imbituba. Os municípios que apresentam maior participação no PIB estadual são: Porto Alegre (17,83\%), Ponta Grossa (3,13\%) e Rolim de Moura (0,03\%). Os que apresentam menor participação no PIB do seu Estado são: Palmeira (0,27\%), Mandaguari $(0,31 \%)$ e Irati $(0,39)$.

Quanto ao Índice de Transparência, observa-se que os municípios mais transparentes da amostra são: Porto Alegre, São José do Rio Preto e Marechal Cândido Rondon. No outro extremo, os municípios menos transparentes são: Ponta Grossa, Paranaguá e Rolin de Moura, que apresenta o menor Índice de Transparência, abaixo da média Nacional, de 3,92, publicada pelo Ministério Público Federal, no Índice de Transparência Nacional Médio para Estados e Municípios.

Em termos gerais, observa-se que alguns municípios se destacam em mais de uma variável demográfica analisada. O município de Porto Alegre apresenta maior população e está entre os municípios de maior PIB municipal, de maior participação no PIB estadual e possui maior Índice de Transparência Municipal. São José do Rio Preto possui a segunda maior faixa populacional e tem o segundo maior índice de transparência municipal. A mesma relação não é observada entre os municípios que apresentam o menor índice de transparência e sua faixa populacional. Ponta Grossa e Paranaguá ocupam a terceira e quarta posição, respectivamente, em termos de faixa populacional, no entanto correspondem ao $2^{\circ}$ e $3^{\circ}$ lugar entre os municípios com pior índice de transparência.

Zanetti, Bonzanini e Ferreira (2020) apontam para a importância da transparência dos órgãos públicos. Reconhecem a transparência como mecanismo operacional para o controle social, pois possibilita ao cidadão o acompanhamento e análise dos atos praticados pelos administradores públicos. Nessa linha, Silva Filho (2017) argumentam que a falta de mecanismos que favoreçam o controle social, ou ineficácia dos mecanismos disponíveis, provocam o desestímulo e a conformação do cidadão frente aos atos de improbidade praticados no âmbito da Administração Pública.

Dessa forma, tornar efetivo o controle social, entende-se que os municípios que apresentam baixo nível de transparência devem criar ou aprimorar seus mecanismos de comunicação com a sociedade, ampliando as opções de participação social.

\subsection{Análise das Variáveis de Eficiência}

Na Tabela 2 apresentam-se os valores de inputs e de output dos OS analisados neste estudo. 
Tabela 2 - Valores de input e output

\begin{tabular}{l|cc|c}
\hline DMU's & INPUTS & Input 2 & $\begin{array}{c}\text { OUTPUT } \\
\text { Economia (R\$ mil) }\end{array}$ \\
\hline Medianeira & 46 & 86 & 6.059 \\
Paranaguá & 18 & 98 & 51.738 \\
Rolim de Moura & 3 & 46 & 5.339 \\
São José do Rio Preto & 8 & 82 & 16.633 \\
Ponta Grossa & 65 & 254 & 28.289 \\
Porto Alegre & 12 & 88 & 15.928 \\
Teresópolis & 16 & 60 & 11.907 \\
Mandaguari & 16 & 163 & 5.602 \\
Arapongas & 8 & 69 & 3.496 \\
Marechal Cândido Rondon & 5 & 270 & 2.096 \\
Irati & 13 & 149 & 4.203 \\
Imbituba & 27 & 137 & 291 \\
Palmeira & 28 & 14 & 15.789 \\
Erechim & 30 & 290 & 2.300 \\
\hline
\end{tabular}

Fonte: Dados da pesquisa.

Os Observatórios Sociais com maior número absoluto de pessoas na equipe de trabalho estão nas cidades de: Ponta Grossa, Medianeira e Erechim. No outro extremo, os OBS com menor número de pessoas são de: Rolim de Moura, Marechal Cândido Rondon, São José do Rio Preto e Arapongas.

O município de Medianeira se destaca com a maior taxa de participação da população no observatório social, observada a partir da relação do número de pessoas que integram o OBS (input 1) sobre a população total do município (Tabela 1). O município apresenta $0,10 \%$ da sua população inserida nesta organização. Porto Alegre, São José do Rio Preto e Rolim de Moura, estão entre os municípios com piores taxas de participação da comunidade em OBS $(0,001 \%$, $0,002 \%$ e $0,005 \%)$.

Portes (2000) argumenta que o volume de capital social de uma comunidade pode ser observado a partir do nível de envolvimento associativo e do seu comportamento participativo, sugerindo a participação da comunidade em associações voluntárias como indicador do capital social. Em geral, os dados apresentados no Input 1 revelam o baixo nível de capital social das cidades analisadas, revelada pela baixa capacidade associativa da sociedade civil, observada no reduzido grau de participação dos cidadãos em relação ao total da população das cidades analisadas.

No entanto, avaliando o potencial de capital social empreendido pelos OBS, estimado pelo produto do número de pessoas que integra o OBS e o número de licitações acompanhado pela equipe, ponderando pela população do município-sede, os OBS que se destacam por seu capital social são: Medianeira, Imbituba e Erechim. No outro extremo, Porto Alegre, Rolim de Moura e São José do Rio Preto são os OBS que empreenderam menor volume de capital social.

Os dados do output utilizado nesta pesquisa revelam que, em termos absolutos, o OBS que gerou maior economia nas licitações acompanhadas foi o de Paranaguá com o valor aproximado de $\mathrm{R} \$ 51$ milhões de reais no ano de 2015. Por outro lado, a menor economia orçamentária foi gerada pelo Observatório de Imbituba, R \$ 291 mil reais. Em termos relativos, ao número de editais acompanhados, o OBS de Palmeira foi o que mais gerou economia orçamentária, alcançando uma economia de aproximadamente $\mathrm{R} \$ 1.127$ reais para cada edital analisado.

Nessa perspectiva, o OBS de Paranaguá deixa de ser aquele que alcançou maior economia aos cofres púbicos e passa a ocupar a segunda posição, com uma economia gerada de aproximadamente $\mathrm{R} \$ 527$ por cada edital acompanhado. Em termos relativos, novamente o OBS de Imbituba foi o que gerou menor economia orçamentária, alcançando o valor aproximado de $\mathrm{R} \$ 2$ por edital. 


\subsection{Eficiência dos Observatórios Sociais}

A Análise Envoltória de Dados considera eficiente as DMUs que apresentam escores de $100 \%$, apresentando dados que lhes estabelecem na posição de fronteira máxima de eficiência. As demais DMUs que não se encontram nesta fronteira são consideradas ineficientes. Entretanto, mesmo que a Análise Envoltória de Dados as considere ineficientes, ainda que as DMUs estejam abaixo da fronteira máxima de eficiência $(100 \%)$, do ponto de vista do controle social, qualquer resultado positivo revela uma eficiência ainda que relativa.

Em se tratando de recursos públicos, a partir da justificativa acima, foram arbitrariamente estabelecidos níveis secundários de eficiência alcançados pelos Observatórios estudados, em que a eficiência média corresponde aos escores localizados no intervalo de $40 \%$ a $99 \%$ e a baixa eficiência encontra-se no intervalo de $0,01 \%$ a 39\%. Na Tabela 3 são evidenciados os escores de eficiência dos OS e os níveis mencionados.

Tabela 3 - Escores dos Observatórios Sociais

\begin{tabular}{|c|c|c|c|}
\hline Nível de eficiência & DMUs & ESTADO & $\begin{array}{c}\text { ESCORES } \\
(\%)\end{array}$ \\
\hline \multirow{2}{*}{ Eficiência Máxima 100\% } & Medianeira & PR & 100 \\
\hline & Paranaguá & PR & 100 \\
\hline \multirow{3}{*}{ Eficiência Média 99\% - 40\% } & São José do Rio Preto & SP & 72,3 \\
\hline & Rolim de Moura & RO & 61,9 \\
\hline & Porto Alegre & $\mathrm{RS}$ & 46,2 \\
\hline \multirow{9}{*}{ Eficiência Baixa 39\% - 0,01\% } & Teresópolis & $\mathrm{RJ}$ & 35,7 \\
\hline & Ponta Grossa & PR & 20,2 \\
\hline & Arapongas & PR & 15,2 \\
\hline & Mandaguari & PR & 14,6 \\
\hline & Irati & PR & 12,2 \\
\hline & Imbituba & $\mathrm{SC}$ & 11,2 \\
\hline & Marechal Cândido Rondon & PR & 10,9 \\
\hline & Palmeira & PR & 2,7 \\
\hline & Erechim & $\mathrm{RS}$ & 0,4 \\
\hline
\end{tabular}

Fonte: Dados da pesquisa.

Os escores de eficiência alcançados pelos OBS variam de $0,4 \%$ a $100 \%$ nas escalas constantes. Dois Observatórios apresentam-se na fronteira de eficiência máxima, três na escala de média eficiência e a maioria, nove, nos escores da eficiência baixa. Do ponto de vista do controle social, é salutar todo resultado positivo alcançado pelos Observatórios em se tratando de recursos públicos, o ganho na economia sob este aspecto é assertivo.

Os dois OBS que alcançaram a eficiência máxima estão localizados no Estado do Paraná, são eles: Medianeira e Paranaguá. Estes OBS conseguiram alcançar melhores resultados (outputs) com menos recursos (inputs). O município de Medianeira já vinha se destacando em algumas análises realizadas acima. Está entre os OBS com maior número absoluto de pessoas na equipe de trabalho e com a maior taxa de participação da população da cidade no OBS. Portanto, partindo do pressuposto de que o volume de capital social de uma comunidade pode ser identificado pelo nível de envolvimento associativo e participativo de uma comunidade (PORTES, 2000), é possível inferir que o OBS de Medianeira concentra maior volume de capital social em relação aos demais OBS analisados.

O conceito de capital social operacionalizado por Fernández e Estrada (2018) é avaliado a partir da capacidade cooperativa dos indivíduos em busca de projetos coletivos em benefício da comunidade. A eficiência do controle social avaliada pela economia gerada nas licitações acompanhadas pelos OBS revela os benefícios obtidos pelos indivíduos em virtude da sua participação em grupos e da construção de sociabilidades, tendo em vista o nível de capital 
social, conforme anunciada por Bourdieu (1980).

Silva Filho (2017) esclarece que o controle social é efetivo quando seus atos conduzem a Administração Pública à observação dos princípios constitucionais da legalidade, moralidade, publicidade e eficiência. A eficiência na administração pública é obtida pela maximização da produção de bens e serviços acompanhada da minimização dos custos. Portanto, a eficiência dos OBS reflete positivamente sobre a eficiência da administração pública.

Cumpre observar ainda, que o OS do município de Paranaguá, que também obteve score máximo de eficiência, pertence a cidade com a quinta maior população da amostra e com maior PIB per capita da amostra, além de ser o OBS que gerou maior economia orçamentária absoluta dentre os OBS analisados. Essa relação entre a eficiência e a população pode estar associada ao que constatado por Netto (2014). Este autor sugere que em municípios de maior porte, as organizações não governamentais atuantes no controle social geralmente possuem menos conflitos com a administração pública, que tende a ser maior em municípios de menor porte. Assim, é provável que ambientes menos hostis sejam mais favoráveis ao alcance de melhor resultado por parte dos OBS.

Os observatórios sociais que alcançaram a faixa da eficiência média estão localizados nos estados de São Paulo, Rondônia e Rio Grande do Sul. Cumpre mencionar que os municípios que se encontram nessa faixa de eficiência (Porto Alegre, Rolim de Moura e São José do Rio Preto) são os que apresentam menor taxa de participação da população no observatório em relação à população total do município. Isso que sugere a presença de outros fatores que podem influenciar a eficiência do controle social além nível de capital social da comunidade avaliada.

A esse respeito, observa-se que Porto Alegre é o município que se destaca nas variáveis demográficas analisadas, como total da população, PIB per capita municipal, participação no PIB do estado e nível de transparência municipal. É provável que os efeitos dessas variáveis possam interferir de alguma maneira na eficiência do controle social deste município.

Nove (9) observatórios encontram-se na escala da eficiência baixa, são eles: Ponta Grossa, Arapongas, Mandaguari, Irati, Imbituba, Marechal Cândido Rondon, Palmeira, Erechim, com os escores abaixo de 39\%. O Observatório Social de Erechim que obteve o menor escore de eficiência representa $1,12 \%$ da sua participação na economia do estado e sua população é de aproximadamente 102 mil habitantes, com 4,90 pontos no índice de transparência municipal.

Também foi constatado que alguns OS de baixa eficiência pertencem aos municípios que estão entre os cinco (5) que se destacam em suas variáveis demográficas. A cidade de Ponta Grossa se destaca pela população e PIB per capita; Teresópolis, por sua população; Erechim, por seu PIB; Marechal Cândido Rondon, pelo PIB e índice de transparência e; Arapongas e Irati, estão no rol de municípios com maior índice de transparência entre os municípios da amostra.

O controle social para ser efetivo requer a otimização do seu exercício, logo, torna-se imprescindível a ampliação e disponibilização dos meios de comunicação entre o Estado e a sociedade civil e os demais órgãos de controle da Administração Pública, para que atuem como parceiros na tarefa de fiscalização da gestão pública. Nesse aspecto, a transparência funciona como mecanismo operacional para o controle social, pois possibilita ao cidadão o acompanhamento e análise da gestão pública e suas operações (ZANETTI; BONZANINI; FERREIRA, 2020).

Para confirmar se os aspectos demográficos estão estatisticamente associados à eficiência dos observatórios sociais, foi gerada a matriz de correlação (Tabela 4) utilizando o teste de Pearson, diante da normalidade dos dados constatada pelos limites observados de assimetria (inferior a 2) e curtose (inferior a 7) estabelecidos por Marôco (2011). 
Tabela 4 - Matriz de correlação (Pearson)

\begin{tabular}{lcccccc}
\hline & EFIC & ECON & PIB & POP & TRANSP & PARTPIB \\
\hline EFIC & 1 & & & & & \\
ECON & 0,5142 & 1 & & & & \\
PIB & 0,2067 & 0,5361 & 1 & & & \\
POP & 0,1640 & 0,2160 & 0,5121 & 1 & & \\
TRANSP & $-0,1036$ & $-0,1533$ & 0,3969 & 0,4559 & 1 & 1 \\
PARTPIB & 0,1338 & 0,1693 & 0,4594 & 0,9506 & 0,2958 & 1 \\
\hline
\end{tabular}

Nota: EFIC: escore de eficiência dos observatórios sociais; ECON: valor da economia per capita obtida nas licitações e pregões acompanhados; PIB: valor do PIB municipal per capita; POP: logaritmo da população; TRANSP: índice de transparência municipal; PARTPIB: percentual de participação do PIB municipal no PIB do Estado. *. A correlação é significativa no nível 0,05 (1 extremidade). **. A correlação é significativa no nível 0,01 ( 1 extremidade).

Fonte: Dados da pesquisa

Com os resultados apontados, constata-se que não há correlação estatisticamente significativa das variáveis demográficas municipais com a economia orçamentária obtida e com o escore de eficiência dos Observatórios Sociais, portanto, a ausência de significância estatística sugere parcimônia na inferência de quaisquer associações entre os fatores demográficos e os resultados alcançados por cada observatório social.

Mesmo assim, cumpre mencionar que as variáveis demográficas se revelaram positivamente associadas ao indicador de eficiência, exceto o índice de transparência municipal que apresentou associação negativa com este indicador. Isto é observável pelo comportamento dessas variáveis nos municípios de Marechal Cândido Rondon, Arapongas e Irati que, mesmo apresentando os maiores índice de transparência não foram os municípios em que os OBS obtiveram maior eficiência.

\section{CONSIDERAÇÕES FINAIS}

O avanço de pesquisas com foco no controle social, que busquem demonstrar sua efetivação através do monitoramento realizado por organizações sociais, é importante para revelar mecanismos e metodologias utilizadas para promover a accountability pública. Nesse sentido, os observatórios sociais atuam como um importante aliado aos órgãos de controle externo no combate à corrupção. Isso é especialmente relevante no momento delicado se encontram o Brasil e o resto do mundo, com a necessidade de implementação de políticas públicas de combate ao novo coronavírus, sendo muitas delas operacionalizadas por meio de gastos públicos. Um contexto como este, aliado ao baixo nível de capital social, torna o ambiente favorável a ações oportunistas de agentes públicos. Isso já está sendo observado pelos supostos casos de fraudes e irregularidades em licitações públicas para contratação de serviços e aquisição de equipamentos destinados a hospitais para combate à pandemia causada pelo novo coronavírus.

Nesse contexto, é oportuno o resgate dos pressupostos teóricos de Putnam (2000) que traz luz à importância do aprimoramento da capacidade associativa da comunidade como forma de promover coesão social em prol da geração do valor público. O capital social é favorecido pela atuação do Observatório Social que fortalece o nível de "civismo" de uma comunidade (Putnam, 2000) ao promover a participação ativa e associação da comunidade e estimular a cooperação na fiscalização e no controle social das condutas públicas. A eficiência desses organizamos, revelada nesta pesquisa, evidencia os benefícios da associação comunitária e a importância do fortalecimento do capital social, principalmente para o combate à corrupção e para a ampliação do bem-estar social. 
Com isso, o presente estudo avaliou o nível de eficiência do controle social obtido pelos Observatórios Sociais sobre os processos licitatórios municipais, utilizando a Análise Envoltória de Dados complementada pela análise dos dados demográficos para o estabelecimento de possível relação entre as características dos municípios e a eficiência do controle social nele exercido. Para atingir os objetivos do estudo, foram analisados os resultados obtidos por quatorze observatórios sociais no ano de 2015. Os dados foram extraídos do site do Observatório Sociais do Brasil, do IBGE e do Ministério Público Federal e discutido por meio da análise cross section para o ano de 2015.

Dentre os observatórios analisados, dois (2) atingiram a fronteira máxima de eficiência no trabalho voltado ao controle social, são eles: OBS de Medianeira e Paranaguá, que pertencem ao Estado do Paraná. A eficiência média foi alcançada por três (3) OBS, são eles: Porto Alegre, Rolim de Moura e São José do Rio Preto. Porto Alegre e São José do Rio Preto. Os demais OBS da amostra: Ponta Grossa, Arapongas, Mandaguari, Irati, Imbituba, Marechal Cândido Rondon, Palmeira, Erechim, alcançaram baixa eficiência no acompanhamento de licitações e pregões públicos.

Os inputs e outputs utilizados para o cálculo da eficiência do controle social foram escolhidos à luz da Teoria do Capital Social que concebe o capital social como um sistema de participação e associação que estimula a cooperação dos indivíduos de uma sociedade e que gera benefícios coletivos em virtude do envolvimento em grupos constituídos para propósitos sociais.

Nesse sentido, o potencial de capital social dos OBS (inputs) foi avaliado pelo produto entre o número de pessoas que compõe a equipe de trabalho do OBS e o número de licitações acompanhadas por elas, ponderados pela população total do município. Os OBS que se destacaram em nível de capital social são das cidades-sede de: Medianeira, Imbituba e Erechim. No outro extremo, os OBS de Porto Alegre, Rolim de Moura e São José do Rio Preto são os que empreenderam menor volume de capital social.

Os resultados dos OBS (outputs) foram avaliados a partir da economia orçamentária gerada aos cofres públicos nas licitações acompanhadas. Em valores relativos, ponderados pelo número de editais acompanhados, o OBS de Palmeira foi o que mais gerou economia orçamentária, poupando aproximadamente $\mathrm{R} \$ 1.127$ reais para cada edital analisado. O OBS de Imbituba foi o que gerou menor economia orçamentária, alcançando o valor aproximado de $\mathrm{R} \$ 2$ reais por edital.

A análise da eficiência do controle social revelou que um dos OBS mais eficientes da amostra (Medianeira) foi, também, o que apresentou maior potencial de capital social empreendido pelo OBS e seu município-sede apresentou nível médio de transparência pública. Por outro lado, o OBS que alcançou o nível baixo de eficiência também está dentre aqueles com maior potencial de capital social, no entanto, pertence aos municípios menos transparentes. Portanto, infere-se que o nível de transparência do município-sede pode ser um importante aliado ao capital social na efetividade do controle social do OBS.

O OBS do município de Paranaguá, que também obteve score máximo de eficiência, pertence a cidade com a quinta maior população da amostra e com maior PIB per capita, além de ser o OBS que gerou maior economia orçamentária absoluta dentre os OBS analisados. Essa relação entre a eficiência e a população pode estar associada ao constatado por Netto (2014), que em municípios de maior porte, as organizações de controle social geralmente possuem menos conflitos com a administração pública, que tende a ser maior em municípios de menor porte. Assim, é provável que ambientes menos hostis sejam mais favoráveis ao alcance de bons resultados por parte dos OBS.

Assim, a análise dos OBS mais eficientes permitiu inferir que o alto nível de capital social empreendido pelo OBS aliado ao nível de transparência das informações públicas e ao 
tamanho do município-sede parecem estar associados aos níveis mais elevados de eficiência do controle social.

De forma geral, concluímos que os observatórios sociais são importantes instrumentos de controle social e que potencializam a formação de capital social das comunidades em que estão inseridos, gerando benefícios econômicos para as administrações públicas locais. A efetividade do controle social exercido pelos OBS está na condução da Administração Pública à observação dos princípios constitucionais da legalidade, moralidade, publicidade e eficiência. Portanto, a eficiência dos OBS reflete positivamente sobre a eficiência da administração pública ao promover o acompanhamento dos atos praticados por gestores públicos e favorecer a compliance e accountability na aplicação de recursos públicos.

Consideramos que há muito que se fortalecer a respeito do capital social das cidades analisadas, por meio dos seus observatórios, pois a participação do cidadão neste tipo de instituição que visa o controle social dos atos praticados pela administração pública ainda é incipiente se comparada ao total da população dessas cidades.

Como limitação da pesquisa destaca-se a impossibilidade de comparar seus resultados com achados anteriores devido ao seu caráter exploratório, que almejou avaliar o nível de eficiência do controle social exercido pelos Observatórios Sociais sobre os processos licitatórios municipais, e a ausência de estudos com propósito semelhante no contexto nacional e internacional.

Cumpre mencionar que a metodologia da Análise Envoltória de Dados apresenta uma limitação ao ser empregada no escopo do setor público, pois os escores classificam as unidades apenas em dois grupos: eficientes e ineficientes, no entanto, qualquer ação que desencadeie na minimização de desperdícios de dinheiro público deve ser considerada como relevante. Portanto, ainda que a análise tenha classificado os observatórios com baixa eficiência, há que se levar em conta o benefício à sociedade promovido pelo trabalho dos Observatórios Sociais no Brasil, tendo em vista que a economia orçamentária gerada a partir do trabalho dos Observatórios é relevante quando se trata da análise de recursos públicos.

Os obstáculos na realização da pesquisa foram encontrados na coleta dos dados que não propiciaram uma melhor análise da eficiência devido à ausência da prestação de contas de alguns Observatórios. Outro aspecto relevante é a ausência de padronização na apresentação do conteúdo dos relatórios. Mesmo os Observatórios Sociais que exigem de órgãos públicos as informações de forma plena, transparente e clara, encontrou-se dificuldade justamente na transparência dessas organizações, em manter suas prestações de contas periodicamente com relatórios disponíveis. Organizações que trabalham e exigem transparência das informações, devem ser exemplos para outras instituições com o mesmo fim ou atividades governamentais.

Recomenda-se, para futuras pesquisas, a utilização de outras metodologias de avaliação da eficiência pública, uma nova análise do desempenho no controle social dos Observatórios Sociais do Brasil com um maior número de observações e uma nova fonte para a coleta de dados, analisando assim mais informações e variáveis de desempenho e eficiência, bem como identificar de forma qualitativa, quais aspectos contribuem com geração das economias expressas nesta pesquisa. Sugere-se também, um comparativo detalhado entre municípios que possuem e não possuem Observatórios Sociais, para avaliar os benefícios atingidos com o trabalho desta organização e, ainda investigar os aspectos políticos que contribuem para a desativação de Observatórios Sociais.

\section{REFERÊNCIAS}

ABRUCIO, F.L.; LOUREIRO, M.R. Finanças públicas, democracia e accountability. In: BIDERMAN, C.; ARVATE, P.R. (org.). Economia do Setor Público no Brasil. Rio de Janeiro: Campus, 2005. 
AGUIAR, A. A construção da cidadania por meio da educação fiscal: uma análise dos observatórios sociais. Dissertação de mestrado, Universidade Federal do Ceará, Fortaleza, Brasil, 2014.

ALBAGLI, S.; MACIEL, M. L. Confiança, capital social e desenvolvimento. Revista Econômica, Rio de Janeiro, 3(2), 283-288, 2001.

ALBAGLI, S.; MACIEL, M. L. Capital social e empreendedorismo local. In: Rede de Sistemas Produtivos e Inovativos Locais. Rio de Janeiro, 423-440, 2003.

ALMEIDA, M.R.; MARIANO, E.B.; REBELATTO, D.A.N. Análise Por Envoltória De Dados - Evolução e possibilidades de aplicação. In: IX SIMPOI - Simpósio de Administração de Produção, Logística e Operações Internacionais, São Paulo, 2006, Anais.

ALVES, M. D. Transparência e Controle Social no Acompanhamento da Aplicação de Recursos Públicos: Atuação do Observatório Social (OS). Biblioteca Digital de Monografias, Brasília, DF, Universidade Aberta do Brasil, 2015.

BAKER, W. E. (1990), "Market networks and corporate behaviour", Am. J. Sociol. 96, pp. 589625.

BAQUERO JACOME, C. M. Construindo uma outra sociedade: o capital social na estruturação de uma cultura política participativa no Brasil. Revista de sociologia e política. Curitiba. N. 21 (nov. 2003), p. 83-108, 2003.

BALDISSERA, J. F.; WALTER, S. A; FRIIST, C; ASTA, D. D. A Percepção dos Observatórios Sociais sobre a Qualidade, Utilidade e Suficiência da Transparência Pública dos Municípios Brasileiros. Sociedade, Contabilidade e Gestão, v. 14, n. 1, p. 113-134, 2019.

BOURDIEU, P. Le capital social: notes provisoires. In. Actes de la recherche en sciences sociales, (31), p. 2-3, 1980.

CARNEIRO, M. A. Instrumentalização do controle social: a experiência da Rede Observatório Social do Brasil. Cuiabá, Escola de Direito FGV, Direito Rio, 2015.

CHARNES, A; COOPER, W.; RHODES, E. Measuring the efficiency of decision making units. European journal of operational research, 1978, 2.6: 429-444.

COLEMAN, J. S. (1988), "Social capital in the creation of human capital", Am. J. Sociol, 94, pp. 95-121.

DE BARROS, A.; CAMARGO, T. Transparency and Control of Government Spending in Brazil: The Role of the Public Expenditure Observatory. In: Open Government and Targeted Transparency: Trends and Challenges for Latin America and the Caribbean. 2012. p. 87.

DE BONA, R. da S.; BOEIRA, S. L. Observatório Social do Brasil e os desafios organizacionais do controle social. Cadernos Gestão Pública e Cidadania, v. 23, n. 75, 2018.

DOIN, G.A., DAHMER, J., SCHOMMER, P.C., SPANIOL, E.L. Mobilização social e coprodução do controle: o que sinalizam os processos de construção da lei da ficha limpa e da rede observatório social do Brasil de controle social. Revista pensamento \& realidade. São Paulo, 27(2), Universidade de São Paulo, 2012.

FERNÁNDEZ, F. E. G; ESTRADA, E. M. Capital social y desarrollo en zonas rurales. Un análisis de los programas LEADER II y PRODER en Andalucía. Revista internacional de sociología, 2018, 60.33: 67-96.

FERREIRA, C., TRECCO, R., CARNEVALE, N. \& OTERO, L. Observatório Social de Suzano: criação e primeiras ações. Arquivos do Mudi, Paraná, 16(1), 2-3, 2012. 
IBGE. Estimativa Populacional de 2015. Recuperado em 18 de novembro, 2016, de https://goo.gl/L6MtaL

INTERNATIONAL, TRANSPARENCY. Corruption perception index 2015: Which countries improved? Which got worse. Berlin, DC: Autor, 2015.

LIU, H. Y.; KOBERNUS, M.; BRODAY, D.; BARTONOVA, A. A conceptual approach to a citizens' observatory-supporting community-based environmental governance. Environmental Health, v. 13, n. 1, p. 107, 2014.

MAMEDOVA, N. A., ALEKSANDROVA, K. S., ALEKSANDROV, N. A., BAYKOVA, A. N.. Information and analytical monitoring support of procurement for public control. International Journal of Applied Engineering Research, 12(19), 8460-8468, 2017.

MARÔCO, J. Análise estatística: com o SPSS Statistics. ( $5^{\mathrm{a}}$ ed.). Lisboa: ReportNumber, 2011.

MINISTÉRIO PÚBLICO FEDERAL. Ranking de Transparência. Combate à Corrupção. Recuperado em 18 de novembro, 2016, em: https://goo.gl/VKNGVx

MONASTÉRIO, L.M. (Tese). Capital social e região sul do Rio Grande do Sul. Universidade Federal do Paraná. Curitiba - Paraná - PR, 2002.

MOTTA, V. C. D. Da ideologia do capital humano à ideologia do capital social: as políticas de desenvolvimento do milênio e os novos mecanismos hegemônicos de educar para o conformismo. Rio de Janeiro: Universidade Federal do Rio de Janeiro, 2007.

NETTO, C. Redes societárias voltadas para o controle social e relação com o estado: uma análise da AMARRIBO Brasil - IFC e OSB. Belo Horizonte, MG, Universidade Federal de Minas Gerais, 2014.

OBSERVATÓRIO SOCIAL DO BRASIL. O que é um Observatório Social (OS)? Recuperado de 14 de julho de 2016 em http://osbrasil.org.br/o-que-e-um-observatorio-social-os, 2015.

OBSERVATÓRIO SOCIAL DO BRASIL. (2017). Institucional. Recuperado de http://osbrasil.org. br/observatorios-pelo-brasil.

PEREIRA, J.M. Reforma do Estado e transparência: estratégias de controle da corrupção no Brasil.VII Congreso Internacional del CLAD sobre la Reforma del Estado y de la Administración Pública, Lisboa, Portugal, 8-11 Oct., 2002.

PORTAL DA TRANSPARÊNCIA. Controle Social. Recuperado em 28 de julho, 2016, de http://www.portaldatransparencia.gov.br/controlesocial/, 2016.

PORTES, A. Capital social: origens e aplicações na sociologia contemporânea. Sociologia, problemas e práticas, 2000, 33: 133-158.

PUTNAM, R. Comunidade e democracia. A experiência da Itália moderna. Rio de Janeiro: Editora FGV, 2000.

QUINTANA, A.C., MACHADO, D.P., QUARESMA, J.C., MENDES, R.C. Contabilidade Pública: de acordo com as novas normas brasileiras de contabilidade aplicada ao setor público e a lei de responsabilidade fiscal. (2a ed.). São Paulo: Atlas, 2015.

SANTOS, E.R., NUNES, M.F. Capital social e políticas públicas: um estudo comparado no Vale do Rio dos Sinos. Revista de Administração Pública, Rio de Janeiro, 50(1), 129-149, 2013.

SCHIFF, M. (1992), “Social capital, labor mobility, and welfare”, Ration. Soc., 4, pp. 157-75. 
SCHOMMER, P.C., MORAES, R.L. Observatórios sociais como promotores de controle social e accountability: reflexões a partir da experiência do observatório social de Itajaí. Revista eletrônica de gestão organizacional, Pernambuco, 8(3), 298 - 326, 2010.

SCHOMMER, P.C., ROCHA, A.C., SPANIOL, E.L., DAHMER, J., SOUSA, A.D. Accountability and co-production of information and control: social observatories and their relationship with government agencies. Revista de Administração Pública, Rio de Janeiro, 49(6), 1375- 1400, 2015.

SILVA FILHO, J. B. da. A eficiência do controle social nas licitações e contratos administrativos. 2017. 123 f. Dissertação (Mestrado em Direito) - Universidade Nove de Julho, São Paulo.

SIRAQUE, V. Controle Social da Função Administrativa do Estado. 1. ed. São Paulo: Saraiva, 2005.

XEREZ, R.; FONSECA, J. R.S. Capital social e redes de vizinhança nas cidades: o caso do bairro de Alvalade. Análise Social, 2019, 232: 562-593.

ZANETTI, J.; BONZANINI, O. A.; FERREIRA, M. M. Transparência e controle social na era da informação: atuação e contribuições dos observatórios sociais no brasil. RTIC-Revista de Tecnologias, Informação e Comunicação, 2020, 1.1: 15-26.

WEHN, U.; EVERS, J. The social innovation potential of ICT-enabled citizen observatories to increase e Participation in local flood risk management. Technology in Society, v. 42, p. 187 $198,2015$. 